\title{
Spontaneous otogenic intracerebral pneumocephalus: case report and review of the literature
}

\author{
Krayenbühl, Niklaus ; Alkadhi, Hatem ; Jung, Hans-Heinrich ; Yonekawa, Yasuhiro
}

\begin{abstract}
Pneumocephalus is commonly associated with head and facial trauma, ear infection or surgical interventions. We describe the rare case of a spontaneous pneumocephalus arising from lateral mastoid air cells. A 48-year-old man presented with a 10-day history of sudden, repetitive, 'hammering-like' acoustic sensations in his left ear that were followed by word-finding difficulties and loss of vision in the right visual field. Imaging revealed a large, left temporal pneumatocele associated with a small acute intracerebral hemorrhage. Left temporal and subtemporal craniotomy and decompression were performed. Further exploration confirmed a dural and osseous defect in the anterolateral surface of the mastoid that was consecutively closed watertight. Although extremely rare, a spontaneous pneumocephalus with mastoidal origin should be considered as a possible diagnosis in patients with suggestive acoustic phenomena and other non-specific neurological symptoms
\end{abstract}

DOI: https://doi.org/10.1007/s00405-004-0754-8

Posted at the Zurich Open Repository and Archive, University of Zurich

ZORA URL: https://doi.org/10.5167/uzh-156181

Journal Article

Published Version

Originally published at:

Krayenbühl, Niklaus; Alkadhi, Hatem; Jung, Hans-Heinrich; Yonekawa, Yasuhiro (2005). Spontaneous otogenic intracerebral pneumocephalus: case report and review of the literature. European Archives of Oto-Rhino-Laryngology, 262(2):135-138.

DOI: https://doi.org/10.1007/s00405-004-0754-8 


\section{Niklaus Krayenbühl • Hatem Alkadhi Hans-Heinrich Jung • Yasuhiro Yonekawa \\ Spontaneous otogenic intracerebral pneumocephalus: case report and review of the literature}

Received: 30 July 2003 / Accepted: 12 January 2004 / Published online: 5 March 2004

(C) Springer-Verlag 2004

\begin{abstract}
Pneumocephalus is commonly associated with head and facial trauma, ear infection or surgical interventions. We describe the rare case of a spontaneous pneumocephalus arising from lateral mastoid air cells. A 48year-old man presented with a 10-day history of sudden, repetitive, 'hammering-like' acoustic sensations in his left ear that were followed by word-finding difficulties and loss of vision in the right visual field. Imaging revealed a large, left temporal pneumatocele associated with a small acute intracerebral hemorrhage. Left temporal and subtemporal craniotomy and decompression were performed. Further exploration confirmed a dural and osseous defect in the anterolateral surface of the mastoid that was consecutively closed watertight. Although extremely rare, a spontaneous pneumocephalus with mastoidal origin should be considered as a possible diagnosis in patients with suggestive acoustic phenomena and other non-specific neurological symptoms.
\end{abstract}

Keywords Spontaneus pneumocephalus - Temporal bone

\section{Introduction}

Pneumocephalus after head and facial trauma, neurosurgical or otologic surgical procedures [1,2], otitis media [3] or tumors of the scull base $[4,5]$ is commonly seen in

N. Krayenbühl $\cdot$ H.-H. Jung

Department of Neurology, University Hospital Zurich, 8091 Zurich, Switzerland

H. Alkadhi (®)

Institute of Neuroradiology, University Hospital,

8091 Zurich, Switzerland

Tel.: +41-1-2558958, Fax: +41-1-2554443,

e-mail: hatem.alkadhi@usz.ch

Y. Yonekawa

Department of Neurosurgery, University Hospital, 8091 Zurich, Switzerland otorhinolaryngiology and neurosurgery. In contrast, cases of spontaneous pneumocephalus originating from the temporal bone have been reported only rarely in the literature $[6,7,8,9,10,11,12]$. Most often, they develop on the basis of a congenital abnormal pneumatised bone surrounding the middle ear that is in communication with the intracranial compartment.

Here, we report the case of a patient with a large, spontaneous, left temporal pneumatocele arising from a normally pneumatized mastoid, which initially manifested with abnormal acoustic sensations, followed by motor aphasia and visual field disturbances. Craniotomy with surgical decompression and obliteration of the fistulous communication ameliorated the symptoms.

\section{Case report}

A 48-year-old, otherwise healthy, right-handed man was admitted to the hospital with a history of sudden, short, 'hammering-like' noise in his left ear that was also noticed by his wife from outside. This sensation was followed minutes later by an acute onset of word-finding difficulties, loss of vision in the right visual field and mild, left-sided headache. Until 10 days prior to this event, the patient's medical history was unremarkable. In particular, there was no history of head trauma, surgery or ear infection. He reported having experienced similar hearing sensations in his left ear several times during the previous 10 days and that a single episode of word-finding difficulties, lasting for minutes, had occurred a week before. At that time an antiplatelet therapy with aspirin was started because a transient ischemic attack was presumed. Neurological examination revealed motor aphasia and a vertical, beam-like deficit in his right visual field. The other neurological functions were normal. An otological examination at the Department of Otorhinolaryngology showed normal findings. Routine laboratory parameters were normal. Cranial computed tomography (CT) obtained on admission revealed a large, space-occupying lesion in the white matter of the left temporal lobe of approximately $4 \times 4 \times$ $5 \mathrm{~cm}$. The lesion had attenuation values of air (Hounsfield units: $-1,000)$ and a small fluid level in its posterior part. Superior to the lesion, a small intracerebral hemorrhage was present. The lesion led to a significant compression of the left lateral ventricle and of the adjacent sulci and gyri; midline shift with signs of uncal herniation and brainstem rotation were present. A high-resolution CT using a bone algorithm demonstrated a close relation of the pneumatocele with air cells in the anterolateral part of the mastoid (Fig. 1a and $b$ ). The temporal bone was fluid free and showed no signs of a 
Fig. 1 a Coronal CT (bone algorithm) reveals the huge, left temporal pneumatocele and the normally pneumatized left temporal bone. b Axial CT scan at the level of the lateral semicircular canal demonstrates the possible communication of the pneumatocele with air cells in the mastoid. c Parasagittal gadolinium-enhanced T1-weighted MRI shows the broad-based contact of the pneumatocele with the anterolateral surface of the temporal bone. No pathological enhancement was present. Note the small associated hemorrhage at the upper border and the fluid level in the posterior part of the lesion. d Coronal T2-weighted MRI demonstrates the space-occupying effect of the cyst and the associated minimal edema
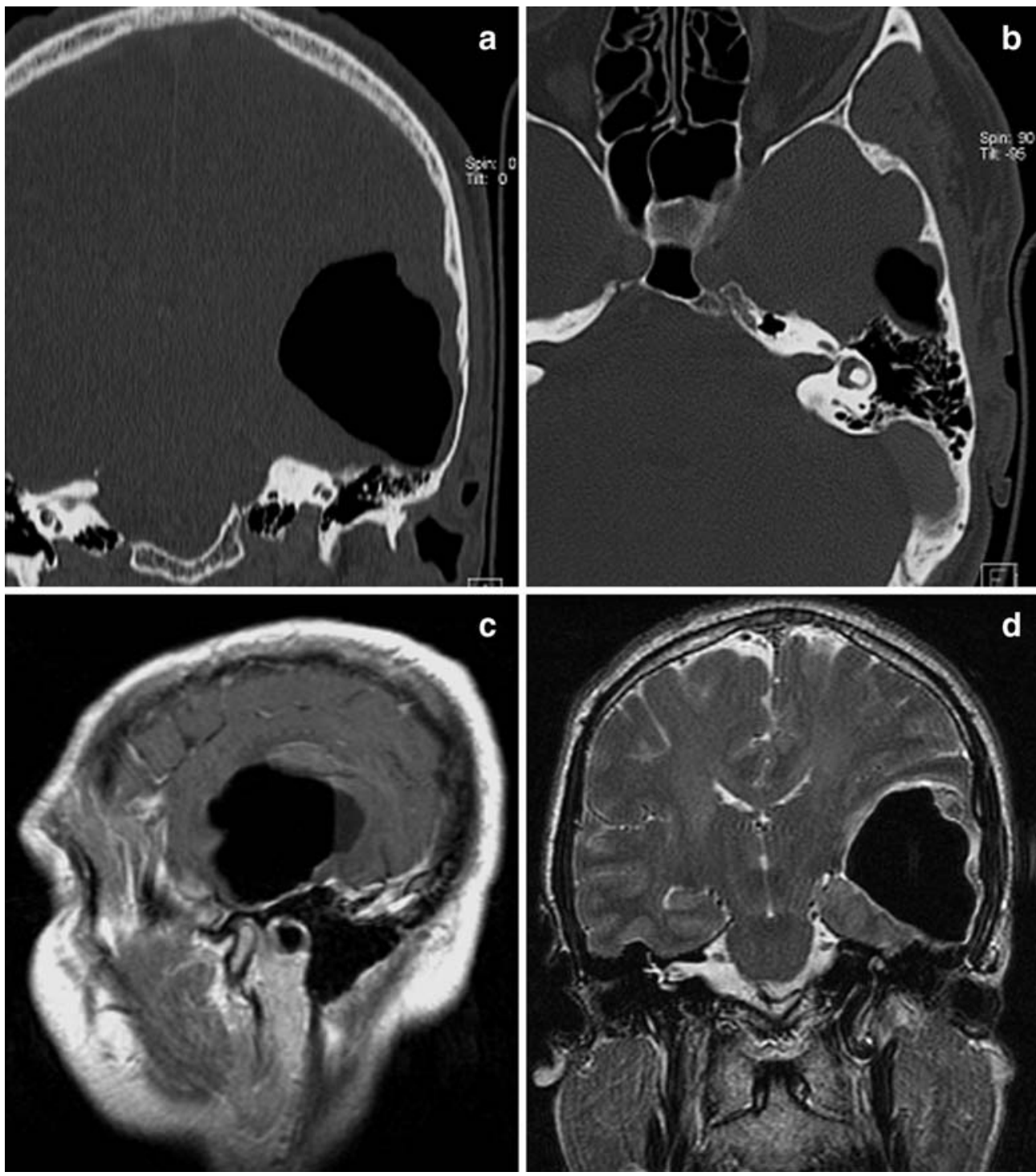

fracture, acute or chronic inflammatory changes. Although no quantitative measurements were performed, the temporal bones showed a normal and symmetric ventilation on both sides. Similarly, magnetic resonance imaging (MRI) showed the large intracerebral pneumatocele in the white matter of the left inferior and middle temporal gyrus with minimal perilesional edema. In particular, no pathological enhancement indicative of an underlying tumor was present (Fig. 1c and d). A left temporal osteoplastic and subtemporal osteoclastic craniotomy was performed to decompress the brain and to seal the presumed communication. After opening the dura, the cortex was pressed out so that the pneumatocele first had to be punctured before further exploration. Air escaped under high pressure, and the cavity collapsed. On the posterior basal part of the inferior temporal gyrus, the cortex was adherent to the dura over approxiamtely $1 \mathrm{~cm}^{2}$ and had to be carefully detached by bipolar coagulation. Some of the tissue removed during this procedure was sent for histological examination. Careful inspection revealed multiple tiny holes in the dura and the underlying bone. These defects were localized lateral and anterior to the arcuate eminence. The bone defects were closed watertight with bone wax, a temporalis muscle fascia flap and fibrin glue. An intraoperative Valsalva maneuver demonstrated air-tight closure of the defects. Pathological examination showed gliosis of the neuronal tissue; no signs of malignancy were found. After the operation, the patient's symptoms gradually improved, and the further postoperative course was un- eventful. The patient was discharged home 5 days after the operation with normal visual fields and minimal speech problems, which were treated with logopedia. The follow-up examination 1 month after demission revealed normal speech and a normal neurological status.

\section{Discussion}

The first description of a pneumocephalus was made in 1884 by Chiari for a patient who died of ethmoiditis [13]. In 1913, Luckett was able to demonstrate intracranial air accumulation in a patient with a scull fracture with the help of X-rays [14]. The common causes of pneumocephalus are heterogeneous and comprise head and facial trauma, ear infections, tumors of the scull base or surgical interventions $[1,2,3,4,5,15]$. In contrast, reports of spontaneous otogenic pneumocephalus are very rare. The first description of a spontaneous cranial aerocele was made in 1954 by Jelsma [16]. To date, only ten other cases have been reported in the literature (see Table 1 ). 
Table 1 Review of the literature of spontaneous pneumocephalus

\begin{tabular}{|c|c|c|c|c|c|c|}
\hline Author year & Sex & Age & Location & Symptoms & Mechanism & Treatment \\
\hline Jelsma 1954 [16] & M & 39 & Subdural occipital right & Hemiplegia, syncope & Spontaneous & Needle aspiration \\
\hline Markham 1967 [15] & $\mathrm{F}$ & 64 & $\begin{array}{l}\text { Subdural, intra-parenchymal, } \\
\text { parietal left }\end{array}$ & Headache, aphasia & Pressure change & Dural repair \\
\hline Madeira 1977 [8] & M & 57 & Epidural, occipital left & $\begin{array}{l}\text { Homonymous } \\
\text { hemianopsia }\end{array}$ & Pressure change & Dural repair \\
\hline Goldmann 1986 [7] & M & 26 & Subdural, frontoparietal left & Headache & Pressure change & Conservative \\
\hline Stavas $1986[10]$ & M & 64 & Intracerebral, temporal left & Expressive aphasia & Spontaneous & $\begin{array}{l}\text { Dural repair, } \\
\text { mastoidectomy }\end{array}$ \\
\hline Spar 1994 [12] & $\mathrm{F}$ & 27 & $\begin{array}{l}\text { Subarachnoid, } \\
\text { intraventricular }\end{array}$ & $\begin{array}{l}\text { Headache, vomiting, } \\
\text { CSF otorrhea }\end{array}$ & Spontaneous & Dural repair \\
\hline Maier 1996 [9] & M & 24 & $\begin{array}{l}\text { Epidural, parietooccipital } \\
\text { right }\end{array}$ & $\begin{array}{l}\text { Headache, visual } \\
\text { scotoma }\end{array}$ & Valsalva & Mastoidectomy \\
\hline Dowd 1998 [6] & $\mathrm{F}$ & 78 & $\begin{array}{l}\text { Intraventricular, intracerebral } \\
\text { temporal right }\end{array}$ & $\begin{array}{l}\text { Hemiparesis, aphasia, } \\
\text { ear noise }\end{array}$ & Spontaneous & $\begin{array}{l}\text { Dural repair, eusta- } \\
\text { chian tube closure }\end{array}$ \\
\hline Park 1998 [24] & M & 49 & $\begin{array}{l}\text { Epidural, temporo-parietal } \\
\text { right }\end{array}$ & Headache & Spontaneous & Dural repair \\
\hline Vallejo 1999 [11] & M & 20 & $\begin{array}{l}\text { Epidural, temporo-occipital } \\
\text { right }\end{array}$ & Headache & Valsalva & Mastoidectomy \\
\hline
\end{tabular}

Two pathogenetic factors have been suggested to be important for the development of a spontaneous pneumocephalus. First, a defect in the temporal bone must be presumed, allowing a communication of air from the mastoid cells to the intracranial compartment. Second, a pressure difference is needed between the temporal bone and the intracranial space to allow the air to enter the cranium. A "ball valve" mechanism might explain the intracranial air accumulation: increased air pressure caused by the Valsalva manoeuvre or ambient pressure changes force air through the fistula into the intracranial cavity. By the consecutive elevation of the intracranial pressure, the brain and dura are forced over the fistula, and the air becomes trapped.

There is a wide variation among individuals in number, size and distribution of the air cells in the temporal bone [17]. The middle ear pressure is presumed to play an important role in the extension of the pneumatization. Constantly increased pressure because of Eustachian tube dysfunction or the habit of performing Valsalva manoeuvres may lead to hyperpneumatization [18]. In addition, defects in the petrous bone might be common in the general population. In his series of 94 autopsy specimens, Ahren found that $21 \%$ had one and $6 \%$ more than five clear defects in the temporal bone [19]. In 6 of the 11 reported cases of spontaneous otogenic pneumocephalus, a distinct event causing pressure changes in the middle ear, such as repetitive Valsalva manoeuvres $[9,11]$, nose blowing [8, 10], altitude change [15] or scuba diving [7], could be described. In the five other cases, no suggestive episodes of elevated middle ear pressure were documented. It is postulated as a possible explanation that also an abnormally low or negative intracranial pressure may lead to air entrapment [5], as is known from some cases after shunt placement $[20,21,22]$. In our patient, the underlying mechanism for the development of the pneumocephalus remains unknown. Although no quantitative measurements were performed with the CT data set in our patient, both temporal bones appeared normal and symmetrically pneumatized. Abrupt pressure changes in the middle ear eventually could be postulated; however, there was no clear anamnestic evidence.

The clinical presentations vary among the reported cases, depending on the location and mass effect of the pneumatocele (see Table 1). Four patients showed epidural, three subdural and four intraventricular, subarachnoid or intracerebral air collection. Our patient heard sudden, "hammering like" noises prior to the onset of motor aphasia and visual field disturbances. Only two cases manifesting with acoustic phenomena have been reported in literature. In one case, the characteristics of the sensation was not further described [5]; in the other, the pneumocephalus manifested with a pulsatile tinnitus 4 years after surgery for an arteriovenous malformation [23]. In the patient in this study, a single episode of word-finding difficulties 1 week before presentation led the referring physician to presume a transient ischemic attack and to initiate an antiplatelet therapy with aspirin. It is most probable that the intracerebral pneumocephalus was already present at that time and that an initial cranial CT would have had led to a correct diagnosis, thereby leading to an early and correct treatment.

Treatment of spontaneous otologic pneumocephalus is usually managed surgically in an attempt to relieve intracranial pressure and to prevent the brain from infection. Most of the cases were treated by closing the existing fistula using muscle fascia flap, cartilage and bone wax to seal the communication from the extracranial to the intracranial compartment $[8,9,10,24]$. An alternative surgical option is to perform an otogenic procedure with puncture of the intracranial air and closure of the mastoid air cells from the temporal bone. An additional therapeutic approach could be the reduction of the pressure in the middle ear by Eustachian tube closure [5]. 
In conclusion, a spontaneous pneumocephalus originating from the temporal bone, although extremely rare, should be considered in patients reporting extraordinary acoustic phenomena and other, non-specific neurological symptoms. The diagnosis is even likely in cases of a normally pneumatized temporal bone and without signs of ear infection or tumor growth.

\section{References}

1. Clevens RA, Marentette LJ, Esclamado RM, Wolf GT, Ross DA (1999) Incidence and management of tension pneumocephalus after anterior craniofacial resection: case reports and review of the literature. Otolaryngol Head Neck Surg 120:579_ 583

2. Di Lorenzo N, Caruso R, Floris R, Guerrisi V, Bozzao L, Fortuna A (1986) Pneumocephalus and tension pneumocephalus after posterior fossa surgery in the sitting position: a prospective study. Acta Neurochir (Vienna) 83:112-115

3. Andrews JC, Canalis RF (1986) Otogenic pneumocephalus. Laryngoscope 96:521-528

4. Brunori A, Bruni P, Delitala A, Greco R, Chiappetta F (1995) Frontoethmoidal osteoma complicated by intracranial mucocele and hypertensive pneumocephalus: case report. Neurosurgery $36: 1237-1238$

5. Rappaport JM, Attia EL (1994) Pneumocephalus in frontal sinus osteoma: a case report. J Otolaryngol 23:430-436

6. Dowd GC, Molony TB, Voorhies RM (1998) Spontaneous otogenic pneumocephalus: Case report and review of the literature. J Neurosurg 89:1036-1039

7. Goldmann RW (1986) Pneumocephalus as a consequence of barotraumas. JAMA 255:3154-3156

8. Madeira JT, Summers GW (1977) Epidural mastoid pneumatocele. Radiology 122:727-728

9. Maier W, Fradis M, Schermet R (1996) Spontaneus otogenic pneumocephalus. Ann Otol Rhinol Laryngol 105:300-302

10. Stavas J, McGeachie RE, Turner DA, Nelson MJ (1987) Symptomatic intracranial pneumatocele from mastoid sinus of spontaneous origin: case report. J Neurosurg 67:773-775
11. Vallejo LA, Gil-Carcedo LM, Borras JM, De Campos JM (1999) Spontaneous pneumocephalus of otogenic origin. Otolaryngol Head Neck Surg 121:662-665

12. Spar JA (1994) Spontaneous CFS communication to the middle ear and external auditory canal: a case report. Acta Radiol 35:506-508

13. Chiari H (1884) Über einen Fall von Luftansammlung in den Ventrikeln des menschlichen Gehirns. Zschr F Heilk 5:383-390

14. Luckett WH (1913) Air in the ventricles of the brain following a fracture of the scull. Report of a case. Surg Gynecol Obstet $17: 237-240$

15. Markham JW (1967) The clinical features of pneumocephalus based upon a survey of 284 cases with report of 11 additional cases. Acta Neurochir (Vienna) 16:1-78

16. Jelsma F, Moore DF (1954) Cranial aerocele. Am J Surg 87: 437-451

17. Dietzel K (1989) Untersuchungen zur "normalen" Pneumatisation des Os temporale. HNO 37:39-47

18. Nyrop M, Bjerre PK, Christensen J, Jorgensen KE (1999) Extensive and symptomatic cranial pneumatization: caused by frequent performance of Valsalva's manoeuvre? J Laryngol Otol 113:480-482

19. Ahren C, Thulin CA (1965) Lethal intracranial complication following inflation in the external auditory canal in treatment of serous otitis media and due to defect in the petrous bone. Acta Otolaryngol 60:407-421

20. Kanner A, Nageris B, Chaimoff M, Rappaport Z (2000) Spontaneous pneumocephalus in the posterior fossa in a patient with a ventriculoperitoneal shunt: case report. Neurosurgery 46: 1002-1004

21. Mylonas C (1991) Delayed pneumocephalus in patients with CSF shunts. Br J Neurosurg 5:67-72

22. Villarejo F, Carceller F, Alvarez C, Bencosme J, Perez Diaz C, Goldman L, Pascual A (1998) Pneumocephalus after shunting for hydrocephalus. Child Nerv Syst 14:333-337

23. Saitoh Y, Takeda N, Yagi R, Oshima K, Kubo T, Yoshimine T (2000) Pneumocephalus causing pulsatile tinnitus. Case illustration. J Neurosurg 92:505

24. Park P, Chandler WF, Telian SA, Doran S (1998) Spontaneous chronic epidural pneumocephalus resulting from hyperpneumatization of the cranium causing mass effect: case report. Neurosurgery 42:1384-1386 